\title{
A centralização política e sua influência no desenvolvimento da sociedade civil angolana*
}

\author{
Rodrigo de SouZa PaIN**
}

\begin{abstract}
Resumo: O artigo pretende apontar os novos caminhos desenvolvidos pela sociedade civil angolana após a passagem da $1^{\mathrm{a}}$ República, caracterizada por um Estado de Partido Único e inspirada nos ideais marxistas e leninistas, para a $2^{\mathrm{a}}$ República, ou seja, para uma economia de mercado e multipartidária. Pretendo explicitar as adversidades advindas das diversas realidades sociais, políticas e culturais do espaço territorial angolano, resultantes do processo de colonização, para a formação e a consolidação da democracia e da sociedade civil em Angola. Para isso foi utilizada uma revisão da bibliografia atualizada sobre o tema e entrevistas em Luanda, concluindo-se que o poder político e administrativo angolano é muito centralizador e inibe a participação da sociedade civil em políticas públicas.
\end{abstract}

Palavras-chave: sociedade civil angolana; democracia; economia de mercado.

\section{Introdução}

A presença portuguesa no território angolano tornou-se mais intensa após o processo da Conferência de Berlim (1884/1885). No entanto, as políticas de ocupação do território foram marcantes ao longo do século XX, basicamente no período do regime de Antonio Salazar, ${ }^{1}$ que trouxe consequiências diretas para as colônias, em especial Angola, a "jóia da coroa portuguesa". A repressão e a exploração do povo

\footnotetext{
* Este ensaio é uma adaptação do capítulo dois da tese de doutorado intitulada Desafios da participação social em um país de conflito agudo: estudo a partir da ONG angolana Acção para o Desenvolvimento Rural e Ambiente (Adra), defendida pelo autor em 25 de junho de 2007 e aprovada pelo Programa de Pós-Graduação de Ciências Sociais em Desenvolvimento, Agricultura e Sociedade (CPDA) da Universidade Federal Rural do Rio de Janeiro. Deixo meu agradecimento às valiosas contribuições do professor Ivan Arruda, da Fapi.

** Doutor pelo Programa de Ciências Sociais em Desenvolvimento, Agricultura e Sociedade (CPDA) da Universidade Federal Rural do Rio de Janeiro e pesquisador associado ao Centro de Estudos Afro-Asiáticos, da Universidade Cândido Mendes (CEAA/Ucam-RJ). E-mail: rodrigo_pain@ig.com.br.

1. Salazar começou a irradiar seu poder em Portugal já nos anos 1920. A Constituição do "Estado Novo" que ele redigiu em 1932 criou um regime "corporativo", nos moldes do que Benito Mussolini acabara de instituir na Itália. Apesar
}

africano foram características marcantes da colonização ao longo do século XX. Nesse contexto, é importante salientar a importância da ditadura de Salazar nas colônias, pois, excluindo as minúsculas possessões espanholas na África, apenas Portugal, como potência colonizadora, vivia um regime autoritário.

A independência angolana chegou depois de conflitos entre os próprios movimentos de libertação nacional ${ }^{2}$ e também contra o poder

de vernizes fascistas como a lei trabalhista de proibição de greves, inspirada no regime de Mussolini, e a implacável polícia secreta, o Estado Novo era essencialmente um regime autoritário católico. Salazar sempre demonstrou extrema aversão pela mudança. O confinamento de Portugal a padrões econômicos e sociais tradicionais foi deliberado. Arcaico e isolado, rejeitando a industrialização por considerá-la um arauto de conflitos de classe e problemas trabalhistas, glorificando uma tradição folclórica e camponesa, o Portugal salazarista estava firmemente escorado contra o século XX. A maioria da população ainda era agrícola, e o regime promovia a família como fonte primária da harmonia social (Maxwell, 2006, p. 35-36).

2. Os três movimentos (MPLA, FNLA e Unita) vinham de realidades coloniais diferentes e, ao contrário das outras possessões portuguesas na África, após a Revolução dos Cravos em Portugal, não houve consenso sobre quem deveria assumir o poder. Portanto, a crise em Angola nasceu (e permaneceu) no próprio surgimento do país, com o conflito armado entre os três movimentos. 
colonial. O nascimento do novo país surgiu no meio de grandes confrontos entre os principais movimentos, que contavam com o apoio de países estrangeiros.

A vitória do MPLA ${ }^{3}$ trouxe um modelo marxista-leninista como sistema sociopolíticoeconômico adotado pelo partido único. $\mathrm{O}$ autoritarismo vivido pela sociedade angolana, a falta da liberdade, a centralização política e o contexto de guerra civil marcaram esse momento.

Em 1991, Angola adere às políticas democráticas, adotando o multipartidarismo, a economia de mercado e a liberdade de expressão. Nesse contexto, conhecido como $2^{\mathrm{a}}$ República (para diferenciar da $1^{\text {a }}$ República de partido único), começam a surgir organizações no seio da sociedade e, ao longo da década, passam a ganhar voz e assumem trabalhos importantes na luta pelo desenvolvimento. Além disso, a sociedade civil angolana manifesta-se de várias maneiras e de forma significativa contrária à guerra entre o governo e a Unita. ${ }^{4}$

Não obstante, depois de tantos conflitos e instabilidades, a sociedade angolana ainda é observada como possuidora de uma cultura que não valoriza o diálogo, sendo a desconfiança um pilar importante nas relações entre pessoas e instituições. As dificuldades que essa sociedade enfrenta, principalmente no que diz respeito às restrições de sua atuação, à dificuldade de inserção na formulação de políticas públicas e ao desenvolvimento de parcerias junto ao governo, caracterizam a sociedade civil ${ }^{5}$ angolana.

3. O Movimento Popular de Libertação de Angola surgiu em 10 de dezembro de 1956 como resultado da fusão de outros partidos e organizações. Sua base de apoio saiu das comunidades de brancos, mestiços e ambundus. Conquistou o poder assim que Angola tornou-se independente. Até hoje permanece no controle do governo.

4. União Nacional de Independência Total de Angola. A Unita foi o último dos três grandes movimentos angolanos a ser fundado (13 de março de 1966). Jonas Savimbi, seu líder, acusou Holden Roberto, líder da Frente Nacional de Libertação de Angola (FNLA), de regionalismo quando trabalhavam juntos. Sua base de sustentação provém dos povos ovimbundus, do Planalto Central angolano, principal grupo étnico de Angola. Esse movimento lutou no conflito armado contra o governo até 2002 de forma quase ininterrupta e ganhou muita força após a independência de Angola.

5. O conceito de sociedade civil aqui utilizado tem influência dos autores Cohen e Arato. Para ambos, tal conceito está no centro das discussões que levaram à constituição da
Diante desse contexto, os atores nãoestatais angolanos têm se empenhando em direção à valorização da democratização e da sociedade civil como agente transformador do espaço social através de ações fundamentais, não empreendidas até então. A reconfiguração do espaço público pela qual passou a sociedade angolana durante a colonização, que foi comandada pelo Estado colonial português de Salazar e, posteriormente, pelo governo do Partido Único marxista-leninista, e o papel da sociedade civil no contexto do conflito armado, que resultou no nascimento da $2^{\mathrm{a}}$ República em Angola, serão objeto de discussão neste artigo, buscando-se, dessa forma, compreender os desafios contemporâneos que a sociedade civil angolana vem enfrentando, agora em um contexto que podemos considerar de "paz".

$\mathrm{Na}$ primeira parte do artigo, apresento a instabilidade política no cenário angolano. A seguir, aponto o surgimento dessa sociedade civil organizada em Angola e sua reestruturação, com a passagem da $1^{\text {a }}$ para a $2^{\mathrm{a}}$ República. Logo depois, saliento o papel da Fundação Eduardo dos Santos e o poder da presidência na política do país. E, finalmente, procuro indicar os desafios enfrentados pela sociedade civil angolana.

\section{A instabilidade política na Angola independente}

A guerra em Angola é complexa, envolveu diversos atores sociais, países estrangeiros, e variou de intensidade em vários momentos. A população sofreu com a exploração e a repressão do poder colonial português, vivenciou o

modernidade ocidental, quando ela revelou-se incapaz de produzir formas de solidariedade a partir de estruturas de coordenação impessoais de ação. Essa necessidade de produzir formas modernas de solidariedade a partir da sociedade civil gerou novas considerações acerca desse conceito. Assim, a sociedade civil, segundo essa concepção, é concebida como a esfera da interação social entre a economia e o Estado, composta principalmente pela esfera íntima, pela esfera associativa, pelos movimentos sociais e pelas formas de comunicação pública. A sociedade civil moderna, criada por intermédio de formas de autoconstituição e automobilização, institucionaliza-se através de leis e direitos subjetivos que estabilizam a diferenciação social. As dimensões de autonomia e institucionalização podem existir separadamente, mas ambas seriam necessárias em longo prazo para a reprodução da sociedade civil (Cohen e Arato, 1992, p. 149-151). 
regime de partido único, a falta de liberdade de expressão e a economia planificada trazida pelo movimento marxista-leninista na $1^{\text {a }}$ República.

Após os Acordos de Alvor, ${ }^{6}$ a posição de Angola como palco do conflito regional armado se acentuou, passando a contar com a intervenção direta de forças armadas regulares dos países vizinhos no interior do país, especialmente a África do Sul. O MPLA continuava com o apoio de forças cubanas e soviéticas; o FNLA, por sua vez, perdeu a assistência financeira americana, ${ }^{7}$ e também o apoio do Zaire (hoje República Democrática do Congo), com o acordo firmado entre Mobutu e o governo angolano do MPLA. E, finalmente, a Unita, o mais fraco dos três movimentos pré-independência, recebeu, ao longo da década de 1980, apoio das Forças de Defesa Sul-Africanas $(\mathrm{SADF})^{8}$ e, com a revogação da Emenda Clark (em 1985), ganhou financiamento dos EUA.

Foram realizados três acordos para o fim do conflito. O primeiro aconteceu depois de intensas negociações no final dos anos $1980 \mathrm{e}$ início de 1990. Os Acordos de Bicesse previam eleições em $1992^{9}$ para escolher o legítimo governo democrático angolano e seus representantes no Legislativo. ${ }^{10}$

6. Acordo entre a ex-metrópole e os três movimentos de libertação nacional (MPLA, FNLA e Unita) em janeiro de 1975, que previa a paz na antiga colônia. No entanto, o acordo não foi respeitado pelos movimentos, instalando-se a guerra civil pela busca do poder em Angola. O MPLA conquistou o poder à força e assumiu em novembro de 1975 , com respaldo de grande parte da comunidade internacional.

7. Com a aprovação da Emenda Clark pelo Senado americano, decretando com isso o fim da assistência clandestina às forças anticomunistas em Angola.

8. A idéia da África do Sul era desestabilizar o governo angolano, que era contrário à política do Apartheid e dava apoio aos guerrilheiros da Organização dos Povos do Sudoeste Africano (Swapo), o movimento de libertação da Namíbia (então colônia sul-africana).

9. Na única eleição que houve em Angola, o presidente José Eduardo dos Santos (MPLA) venceu no primeiro turno o candidato da Unita, Jonas Savimbi. No entanto, este último não aceitou o resultado, alegando fraude (o que não foi constatado pelos observadores internacionais), recusandose a participar do segundo turno, o que mergulhou o país novamente numa guerra sangrenta (inclusive na capital e nos arredores) depois de alguns meses de trégua por causa das eleições.

10. Foi a partir desses acordos que o governo angolano abandonou o modelo socialista, como também os países estrangeiros que ainda atuavam em partes do território angolano passaram a desocupar a região.
Com o retorno da guerra após o fracasso das eleições em Angola, a comunidade internacional novamente tentou buscar o diálogo na tentativa de obter a paz. Com isso, em 1994, surge o Protocolo de Lusaka, em outra tentativa de impedir o conflito entre as partes beligerantes. No entanto, não houve respeito a diversos pontos, tanto pelo governo como pelo movimento armado. O período em vigor do protocolo era conhecido entre os angolanos como um tempo "nem paz, nem guerra", devido ao clima de instabilidade e aos conflitos periódicos.

Diante disso, pode-se afirmar que a guerra aumentou de intensidade no fim da década de 1990. As ligações entre as cidades do litoral e o interior agrícola enfraqueceram, a ponto de quase desaparecerem. As cidades, em especial Luanda (cuja população cresceu muito após o início dos conflitos), sobreviviam com alimentação importada, em lugar da produzida nacionalmente. As zonas rurais foram negligenciadas e deixadas às suas próprias estratégias de sobrevivência (Meijer, 2006, p. 2).

Nessa altura, o governo financiava a guerra através de vendas antecipadas de petróleo vide o caso Angolagate, no qual o governo angolano, entre 1993 e 2000, sem o apoio da desmembrada URSS, e enfraquecido diante da Unita, buscou comprar armas vindas do Leste Europeu com vários contratos ilegais, através do apoio de altos escalões do governo francês de François Mitterrand. No que diz respeito ao movimento armado, mesmo recebendo diversas sanções da ONU, estas pouco adiantavam, porque a organização controlava terras com reservas de diamantes, as quais abasteciam seu exército com a exportação ilegal para países vizinhos (Vines, 1995, p, 28).

Em fevereiro de 2002, morre em combate o líder da então enfraquecida Unita, Jonas Savimbi, na província de Moxico. Com isso é assinado o Memorando de Luena, que finalmente coloca fim ao conflito. No entanto, nem todos os confrontos em Angola se encerram com o memorando. Em Cabinda, região norte do país e um enclave territorial rico em petróleo, permanecem as tentativas da Frente de 
Libertação do Enclave de Cabinda (Flec) de separação da região do restante de Angola. ${ }^{11}$

\section{A sociedade civil angolana no contexto da $1^{\text {a }}$ República}

A sociedade civil angolana tem uma história que é anterior ao dia da independência do país. Não se pode conceber a data de 11 de novembro de 1975 como sendo o marco da história do surgimento da sociedade civil organizada em Angola. De acordo com Carlos Lopes, a "inferioridade africana" tem por base a idéia da inexistência do fato histórico antes da colonização. Para o autor, o "desenvolvimento da história do continente é patente. Tudo quanto está ligado a um passado de descobertas e realizações africanas é desapropriado deles e repassado a outro povo" (Lopes, 1995, p. 22-23).

O africanista Nelson Pestana, por exemplo, não considera o próprio nacionalismo moderno angolano, que inspirou a luta armada entre os anos 1950/1960, como ponto de partida da conformação da sociedade angolana. Para ele, existe uma "história antiga" dessa sociedade que tem ligação imediata com a história do movimento associativo angolano, cujas origens estão situadas nas associações culturais e nos movimentos cooperativistas e mutualistas de meados do século XIX e que deram corpo à afirmação do direito de cidadania dos africanos nos anos 1930, prolongando-se ao longo de todo o século XX (Pestana, 2004, p. 3).

Sobre o associativismo angolano do século XIX, Aida Freudenthal aponta que, através da imprensa (que surge com significativo impacto entre a elite da Angola colonial no final do século XIX), as elites passaram a participar das críticas formuladas à administração colonial, reivindicando direitos, denunciando abusos e desencadeando o temor e o ódio dos colonos, cujos interesses estavam em contradição com as disposições legais, nomeadamente no que dizia respeito à imposição do trabalho obrigatório e as suas duras condições. Essas elites fizeram ouvir a sua voz através da imprensa não só em Angola,

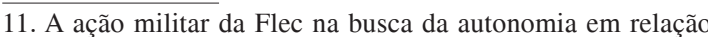
ao resto do país ocorreu numa escala bem menor do que da Unita, o que explica por que ele tenha recebido menos atenção. Suas ações foram mais políticas que militares. mas também em Lisboa, reforçando assim as bases de sua identidade (Freudenthal, 1988, p. 19). ${ }^{12}$

Para Pestana, a história mais recente da sociedade civil angolana tem a ver com o "renascer" desse movimento associativo, com a reafirmação da sua autonomia, da sua legitimidade e de sua intervenção no espaço público depois que os movimentos de libertação abandonaram o espaço público criado no contexto colonial e se assumiram como partidos-nação, ou seja, como representantes de todo povo angolano $^{13}$ (Pestana, 2004, p. 3).

Ademais, faz-se necessário afirmar que a configuração do espaço público em Angola foi comandada pelo Estado desde a época colonial. Assim sendo, os severos limites impostos à participação $^{14}$ de atores não-estatais impediram a construção social de uma cultura do diálogo e ignoraram a contribuição de mecanismos promotores de coesão social, particularmente de normas sociais complementares à racionalidade do Estado e do mercado (Elster, apud Abreu, 2006, p. 28).

De acordo com Basil Davidson, o regime português foi um órgão de repressão sistêmica em nível interno e reproduziu as mesmas misérias na África, concedendo poucos direitos cívicos aos seus próprios cidadãos e, praticamente, nenhum direito válido aos seus "nativos". As vicissitudes em termos de política ou de método nunca foram temas de debates no seio desse império, mas, sim, uma provocação para a polícia política $^{15}$ (Davidson, 2000, p. 184).

Assim, fica difícil falar em participação da sociedade civil no contexto da época colonial. Manifestações fizeram-se presentes, principal-

12. Freudenthal chama atenção para o jornal $O$ negro, publicado em Lisboa em 1911, que atuou como porta-voz do Partido Africano, através do qual a elite africana lá residente expôs os seus protestos e as suas aspirações sobre o futuro das colônias e os direitos dos africanos (1988, p. 19).

13. Isso não se restringiu apenas a Angola, mas a muitos movimentos de libertação de outros países colonizados.

14. Eis a dificuldade de compreensão do conceito de sociedade civil, principalmente quando os autores que se debruçam sobre a temática buscam um conceito definido, sem compreender as diversas dinâmicas e os diversos atores sociais e políticos que atuam na complexidade da sociedade analisada, a angolana, no caso.

15. Polícia Internacional e de Defesa de Estado (Pide), ou seja, a polícia secreta portuguesa no período colonial. 
mente através dos movimentos de libertação nacional, mas, no entanto, a conjuntura autoritária dificultava qualquer tentativa de participação por parte da população.

Em relação às análises sobre a "sociedade civil" angolana no período de vigência do regime do Partido Único em Angola (pós-independência, 1975-1991), encontramos reflexões geralmente reducionistas, compelidas em negar qualquer existência de uma autonomia latente, ou exclusivamente legitimadoras, transformando as organizações de massas criadas pelo próprio governo do MPLA como exemplos - a Organização das Mulheres Angolanas (OMA), a União Nacional dos Trabalhadores de Angola (Unta) em pseudo-representantes dessa "sociedade civil". ${ }^{16}$

Outro elemento importante a se considerar na busca da compreensão da sociedade civil angolana naquele contexto é a própria guerra civil que, nas duas primeiras décadas após a independência, inibiu o desenvolvimento de organizações autônomas atuando no espaço público. Dessa forma, toda a tentativa de autonomização da sociedade civil foi também esmagada pela guerra, na medida em que a deslegitimação do poder do Estado não reforçou o poder da sociedade civil; ao contrário, fortaleceu um outro poder, armado e de natureza totalitária que, em contrapartida, deu novo fôlego à máquina estatal, quando a rejeição ao poder armado contribuiu, para bem ou para mal, para o seu reforço e para o conseqüente enfraquecimento das organizações autônomas.

Toda essa configuração da história política de Angola é importante para entendermos por que seu espaço público não pode ser concebido como um espaço neutro. Esse espaço tem a sua própria história (traumática) que influencia fortemente a capacidade dos angolanos de se organizarem e de falarem publicamente (Comerford, 2005 , p. 3). Munslow afirma que

É necessário estudar de novo a história [de Angola] para se entender o espaço limitado que existe para a sociedade civil prosperar em

16. Pestana procura traçar a genealogia analítica dessa realidade que ainda não ousa dizer seu nome e que, por vezes, é designada como o conjunto dos cidadãos sem partido (2004, p. 15).
Angola. Durante o domínio colonial reprimiramse as organizações africanas independentes [...]. No meio das fileiras do MPLA, a tentativa de golpe de Estado de Nito Alves ${ }^{17}$ em maio de 1977 teve enormes ramificações para impedir o futuro crescimento da sociedade civil em Angola. (Munslow apud Comerford, 2005, p. 3)

Todo o trauma de longos anos de guerra mergulhou a sociedade angolana em uma espécie de "cultura da violência e do medo", que se refletiu na falta de participação, na omissão e na submissão por parte dos angolanos em determinadas situações. Adão Avelino Miguel, filósofo e docente da Universidade Católica de Angola, salienta, ao analisar a conjuntura atual, que se percebe claramente uma manifesta falta de participação e de envolvimento na execução das tarefas sociais e culturais, pressentindo-se a ausência de motivação para realizar e implementar planos e projetos comunitários. Sente-se a falta de disposição, dedicação e abnegação na realização e no cumprimento das tarefas sociais (2006, p. 26). $\mathrm{Na}$ verdade, só poucos fazem o muito que todos deveriam fazer. ${ }^{18}$

Ainda assim, na conjuntura do Partido Único, o espaço literário angolano - representado na figura da União dos Escritores Angolanos (UEA), nascida em um clima, ao mesmo tempo, de lutas internas no seio do poder político e da ânsia pela (re)estruturação do campo literário e cultural autônomo - foi o ambiente em que se pôde desfrutar de uma relativa independência naquilo que dizia respeito ao controle do espaço público por parte do Estado, ${ }^{19}$ constituindo-se como uma fonte de legitimidade independente (Pestana, 2004, p. 10).

17. Seguindo esse raciocínio, podemos relacionar o violento conflito que se seguiu após as eleições de 1992, provocando milhares de mortes (em apenas dois dias), assim como, em 1977, a tentativa de golpe de Estado dentro do próprio seio do MPLA, reprimida de forma violenta, com milhares de mortes marcando fortemente a sociedade civil angolana.

18. Percebemos que até hoje o eco de tanto autoritarismo imposto à população ainda tem significativo impacto na sua participação em ações sociais.

19. Na época, alguns dos maiores nomes da cultura nacional, em conseqüência da forma violenta como eram resolvidas as diferenças (ou contradições) políticas ou de personalidade no interior do MPLA, tinham se distanciado dos círculos do poder, também sido marginalizados ou eram, ainda, objeto de severo esquecimento. 
Essa instituição foi importante, pois liderou o esforço de (re)estruturação do campo literário, definindo-se como uma organização de intelectuais que defendia a revolução trazida pelo governo, ao mesmo tempo em que reclamava a legitimidade de representar todos os escritores angolanos, pretensão reveladora de uma contradição nos próprios termos e que escondia mal o espírito confederador que ela pretendia desempenhar.

Desta maneira, como afirma Pestana, a União dos Escritores Angolanos era o lugar onde evoluía essa contradição entre "autonomia literária" e "controle político"; ao mesmo tempo em que proporcionava uma relativa autonomia do espaço literário em face do controle do Partido Único e do Estado, permitia esforços redobrados das elites políticas com vistas à instrumentalização política da literatura e dos escritores $^{20}$ (Pestana, 2004, p. 11).

\section{A sociedade civil angolana organizada na $2^{\text {a }}$ República}

Mudanças significativas ocorreram com a transição da República Popular de Angola para a República de Angola, em 1991. A passagem para o Estado multipartidário democrático de direito trouxe enormes transformações no quadro jurídico do país, criando leis importantes, como a Lei das Associações (com seu funcionamento independente do Estado), a Lei dos Partidos Políticos Independentes, a Lei do Direito à Greve, a Lei de Liberdade de Imprensa, a Lei de Reunião Pacífica, entre outras.

A simples observação das designações desse pacote de leis nos revela como era a ocupação do espaço público pelo Estado durante a $1^{a}$ República. A socióloga Cesaltina Abreu aponta, por outro lado, a falta de regulamentação ou a regulamentação tardia dessas leis, observável nas datas de suas respectivas aprovações,

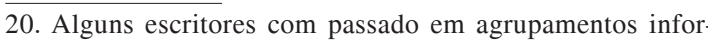
mais de esquerda criaram, abertamente, uma associação cultural em Luanda que publicou, conforme aponta Gonçalves, a revista literária Archote, animando interessantes debates nos quais se combatia o monolitismo do regime na cultura sendo decisiva na constituição da Associação Cívica Angolana (2004, p. 27). Fundada em 1990, a primeira ONG angolana tinha como vocação a defesa dos direitos humanos. o que gerou desentendimentos na sua interpretação $0^{21}$ (Abreu, 2006, p. 34).

Em 1994, três anos após o surgimento da $2^{\mathrm{a}}$ República em Angola, Fernando Pacheco, presidente de uma das maiores ONGs angolanas (Acção para o Desenvolvimento Rural e Ambiental - Adra) ${ }^{22}$ afirmava já existir uma sociedade civil angolana "como a expressão de forças sociais e econômicas formais e não formais que já demonstravam capacidade de assegurar, pelo menos, a sobrevivência das cidadãs e dos cidadãos" (Pacheco, 1994, p. 7).

Assim, Pacheco não tinha dúvida que já existia uma afirmação de sociedade civil angolana que era constituída por forças sociais (associações informais, redes de parentesco, indivíduos dotados de espírito empreendedor) resultantes de um processo de urbanização recente. Essas forças estavam em rápida e permanente transformação porque tinham acesso às diferentes modernidades, não isoladas, e estavam em permanente contato com o mundo através dos meios de comunicação, das linhas áreas internacionais, estabelecendo laços múltiplos entre si e construindo redes de autênticos contrapoderes, traduzidos em fatos conhecidos como a organização dos mercados, o estabelecimento de taxas de câmbio, as ações de reivindicações, entre outros (Pacheco, 1994, p. 7).

No entanto, essa sociedade civil esteve ausente nas negociações de paz no Protocolo de Lusaka. Apenas os militares tiveram assento nas mesas de negociação; os outros atores políticos desarmados foram impedidos de participar, o que não privilegiou a verdadeira reconciliação nacional.

Muitos autores, como o ganense Gyimah Boodi, afirmam que a sociedade civil organizada na África tem crescido em um ritmo muito rápido. Lopes considera que, no caso angolano, essa afirmação é exagerada. Todavia, consoante

21. Como exemplo, a nova Lei de Terras aprovada em 2004 revogando a Lei 21-C/92s, de 1992 (sobre o uso e aproveitamento da terra para fins agrícolas).

22. ONG angolana fundada em 1991, com trabalhos que envolvem a valorização da cultura local, o desenvolvimento sustentável, a preocupação com a educação e a participação direta das comunidades em projetos. Trata-se de uma organização conceituada em Angola, devido à seriedade, à independência em relação ao governo e à sustentabilidade de suas ações. 
o autor, a sociedade angolana constitui, seguramente, o segmento social de maior crescimento e dinamismo em Angola desde o início da construção da democracia nos primeiros anos da década de 1990 (Lopes, 2004, p. 2).

Em 1996, é criada a Fundação Eduardo dos Santos (Fesa), uma ONG que tem o nome e o patronato do presidente da República de Angola (José Eduardo dos Santos). É uma organização que dizia inspirar-se em instituições similares existentes nos grandes países democráticos e que afirmava pretender consolidar, como estas, os objetivos de progresso social, cultural e científico em Angola. ${ }^{23} \mathrm{~A}$ Fesa surge, mais claramente, como uma instituição na qual o presidente da República intervém como pessoa privada e cujos recursos não são os seus, mas sim os de grandes sociedades internacionais e nacionais. ${ }^{24}$

Essa fundação pode ser analisada em um primeiro nível, de acordo com Christine Messiant, como um produto e uma coroação do sistema geral de dominação clientelista, além de ser, também, um sinal de tentativa de reforço do poder presidencial. ${ }^{25}$ Basicamente, ela "retém" dinheiro público que não é seu para realçar a imagem pessoal de benfeitor do seu "fundador e patrono", que nela intervém como pessoa privada, mas que é também, como não deixa de lembrar a fundação, "o Presidente da República de Angola e do MPLA, o partido majoritário no poder", ou seja, o Estado.

Para tal, a Fesa, como "Estado" angolano, atua na gestão estratégica do petróleo do país, rivalizando com os interesses econômicos estrangeiros e as empresas estatais. A "taxa" (direito de entrada, contribuição em diversos projetos) é aplicada na instituição pelas grandes companhias estrangeiras interessadas nos "negócios" angolanos (as sociedades petrolíferas e para-petrolíferas, as implicadas nos diamantes e nos grandes projetos de infra-estrutura, o setor de construção, certos bancos, entre outros) e também nas grandes sociedades angolanas

23. Mais informações na página da instituição na internet: http://www.fesa.org.br/.

24. Basta ver as mensagens dos patrocinadores das revistas publicadas pela instituição. É comum encontrar a brasileira Odebrecht, as estatais Sonangol (petróleo) e Taag (aviação).

25. É clara a referência ao culto à personalidade do presidente José Eduardo dos Santos. (como nas estatais Sonangol, do petróleo, ${ }^{26} \mathrm{e}$ Endiama, dos diamantes, sociedades que sempre dependeram diretamente, não das decisões do governo, e sim do presidente), bem como em diversas outras menores que também pretendem figurar neste "bloco" duplamente interessante, porque os aproxima consideravelmente do poder e das benesses ${ }^{27}$ (Messiant, 1999, p. 8).

Destarte, o presidente angolano "recanaliza" em direção à sua própria pessoa uma parte dessas benesses e as redistribui, todos os anos, sob a forma de "cacho", durante a "semana da Fesa", ${ }^{28}$ que dá lugar a muita publicidade, votos de felicidades e agradecimentos. A fundação não funciona apenas com fundos privados. Dentre as realizações ostensivamente inauguradas, algumas provêm do próprio Estado. ${ }^{29}$

A Fesa colabora com o "Estado", os ministérios ou as administrações locais, intervindo em complemento à "ação do governo". Ademais, apóia, outrossim, uma série de outras organizações da sociedade civil (algumas surgem na própria semana da fundação). Também ampara a Associação de Apoio às Mulheres Rurais e o Fundo Lwini, ${ }^{30}$ as duas tendo a primeira-dama,

26. De acordo com documentos de investigação da ONG americana Human Rights Watch, "[...] em certos casos recentemente observados, as receitas de petróleo não foram processadas nem pelo Ministério das Finanças, nem pelo Banco Nacional de Angola, passando antes pela companhia petrolífera estatal, Sonangol, ou pela Presidência da República, tendo sido utilizadas secretamente para aquisição de armamentos. Estas ocorrências originaram também alegações de corrupção no setor público [...]" (Human Rights Watch, 2002, p. 5).

27. Até então, essas grandes sociedades estavam, e ficavam cada vez mais abandonadas pelos serviços públicos do Estado, implicadas em obras colaterais às suas atividades (estradas, água, eletricidade, infra-estrutura diversa, escolas, centro de saúde), mas em seu próprio nome (Messiant, 1999, p. 8).

28. Forma velada pela qual a instituição celebra o aniversário (em agosto) de seu patrono, o presidente José Eduardo dos Santos.

29. Sabe-se que o centro de crianças abandonadas de Cacuaco, inaugurado em agosto de 1998, foi financiado pelo governo angolano e que os ministérios, ou ainda o governo provincial de Luanda, contribuíram também para o financiamento de diversos projetos (Messiant,1999, p. 9).

30. Inspirada na visita da princesa Diana em Angola (janeiro de 1997), a primeira-dama criou o Fundo Lwini, em junho de 1998, com o objetivo de angariar fundos para a execução de ações de apoio às vítimas de minas terrestres. Entre as entidades que aderiram ao Fundo Lwini por meio de compromisso financeiro, estão estatais como a Sonangol e a Endiama, empresas petrolíferas internacionais como a Elf, empresas diamantíferas internacionais como a sul-africana De beers e, claro, a Fesa. 
Ana Paula dos Santos, como presidente. Ela cofinancia, com diversos ministérios, essa organização econômica e apadrinha, ainda em associação com vários ministérios, aquela fundação de proteção à natureza. Ainda financia ou cofinancia e apóia, ocasionalmente, um certo número de associações nacionais, locais e de ordens profissionais (Messiant, 1999, p. 10).

Foi ao falar das dificuldades financeiras vividas pela Adra que Luis Monteiro, diretorgeral da instituição, afirmou que poderia chegar à Fesa e dizer "precisamos de dinheiro". Mas, por julgar que a Fesa não contribui para a construção da democracia em Angola, a Adra jamais pediu auxílio à fundação. ${ }^{31}$ Ademais, é comum ouvir de ONGs angolanas a dificuldade que enfrentam em termos de financiamento. Para citar um exemplo, o secretário-geral da Liga Internacional da Defesa dos Direitos Humanos de Angola, João Castro "Freedom", apontou com destaque a escassez de recursos financeiros como o maior obstáculo para a implementação com plenitude de seus projetos e programas. ${ }^{32}$

A Fesa, assim, é uma evidência da privatização do Estado e de centralização do poder angolano em relação àquele e da desagregação deste mesmo Estado. Com ela, "o engenheiro José Eduardo dos Santos" assume, de alguma maneira, a "cabeça" da sociedade civil angolana, e, sintomaticamente na posição de "patrono", utiliza trunfos incomparáveis de um presidente da República.

O período pós-Lusaka (1994) marca o início daquilo que se tornou um engajamento significativo na busca pela paz pelas organizações da sociedade civil de Angola, na forma de promoção dos direitos humanos. ${ }^{33}$ Iniciativas importantes da sociedade civil organizada angolana rumo à busca da paz duradoura fizeram-se presentes após o fracasso do protocolo. ${ }^{34}$

\footnotetext{
31. Em entrevista em Luanda, 7 de dezembro de 2006.

32. Em entrevista em Luanda, 30 de novembro de 2006.

33. Por estar "ausente" nos Acordos de Bicesse (1991), a promoção dos direitos humanos constituiu uma componente muito importante no Protocolo de Lusaka. Segundo Vines, muitas organizações preferiram chamar seus trabalhos em direitos humanos de "educação cívica", um termo muito menos controverso aos olhos do governo (Vines, 1998, p. 25).

34. Vale a pena lembrar que muitas organizações surgiram após o Protocolo de Lusaka, daí a crescente forma de atuação da sociedade civil organizada em Angola.
}

Desse modo, organizações não-governamentais internacionais e nacionais, igrejas, movimentos comunitários, associações culturais e profissionais, entre outras, solicitaram ao governo angolano e à Unita que agissem juridicamente, e dentro do quadro constitucional, em defesa dos direitos humanos dos cidadãos angolanos comuns. Esse discurso, que partiu do seio da sociedade para as partes em guerra constituiu um apelo pela lei e pela ordem. Isto inverte o argumento comum segundo o qual o Estado é que vive a solicitar dos cidadãos o respeito à lei e à ordem. Nesse momento, a sociedade civil é quem solicita do Estado angolano e da Unita que procedam dessa forma (Comerford, 2005, p. 153).

A nova retomada da guerra em $1998 \mathrm{fez}$ com que a sociedade civil produzisse uma série de documentos. Michael Comerford, consultor da Workshop Development, tradicional ONG canadense em Angola, e autor da tese de doutorado As narrativas angolanas da paz, de Bicesse até a morte de Savimbi, chamouos de "apelos de paz", apontando-nos três importantes documentos. O primeiro, de 1999 , chamado Manifesto para a paz em Angola, assinado por 120 pessoas, incluindo jornalistas, sociólogos, docentes universitários, advogados, músicos, deputados, entre outros. O segundo, de abril de 1999, realizado pelo Grupo Angolano de Reflexão e Paz (Garp), que incluía entre os seus membros pessoas ligadas ao campo religioso e ao meio político e dos meios de comunicação. $\mathrm{O}$ documento proclamava que "ninguém tem o direito de falar em nome do povo para fazer a guerra civil, seja esta com o argumento de defesa ou resistência. $O$ povo não foi consultado". Interessante notar que os integrantes de ambos os movimentos sentiram-se discursando para um grupo mais amplo do que a própria sociedade civil organizada ou de atores da esfera pública, falando em nome do povo angolano para aqueles que fizeram a guerra em seu nome (Comerford, 2005, p. 153-155).

O terceiro foi um apelo feito em 2000, pela Mulheres Pela Democracia (MPD), uma ONG formada por mulheres profissionais, como advogadas, jornalistas, empresárias, entre outras, que estudaram no exterior, com bolsas financiadas pelo governo. Esse documento se aproxi- 
ma dos outros dois, mas é elaborado a partir da perspectiva das mulheres angolanas e traz um sentimento de tristeza que não deriva somente da continuação da guerra, mas do fato de que as mulheres, como esposas e mães, tinham perdido maridos e filhos durante o conflito.

$\mathrm{O}$ que vale em todos esses documentos, segundo Comerford, é a explicitação de um reconhecimento crescente de que a sociedade civil tinha um papel fundamental na resolução do conflito (2005, p. 155). Isto refletiu um sentimento coletivo de que "o problema é nosso", ausente no passado na busca pela paz.

Todas essas questões aqui apontadas envolvem uma série de características específicas da sociedade angolana que devem ser levadas em consideração. A sociedade civil na África é um campo muito mais contraditório do que pretende o discurso ocidental dominante, pois este privilegia de forma simplista os conflitos entre Estado e sociedade civil, romantizando a segunda como um baluarte da democracia. As formas de relacionamento de indivíduos e grupos da sociedade civil com o Estado variam da acusação, quando os seus interesses são postos em questão, à aliança e à cooperação, quando para tal têm oportunidades e vantagens (Abreu, 2006, p. 117).

É importante salientar que a maioria dos grupos e organizações da sociedade civil na África é dependente da comunidade internacional, tanto para efeitos de financiamento quanto para a aprovação de seus programas de ação, acabando por incorporarem, acriticamente, conceitos e práticas sem a necessária reflexão quanto à sua adequação ao contexto no qual vão ser aplicados (Abreu, 2006, p. 117). O modelo ocidental é trazido e aplicado na maioria das vezes sem levar em consideração aspectos relevantes das culturas africanas. Diversas ONGs negligenciam características importantes da cultura local, negando a importância do multiculturalismo em prol de concepções globais de desenvolvimento, o que gera conflitos em regiões tradicionais da África (Pain, 2006, p. 42).

\section{Fim do conflito armado e os desafios da sociedade civil angolana no contexto de centralização político-administrativa}

Mesmo com o fim do conflito armado em Angola, é importante levar em consideração a dificuldade existente na comunicação entre o governo e a sociedade civil no que se refere ao planejamento de políticas públicas. ${ }^{35}$ Embora oficialmente se considere que os novos instrumentos legais (como as novas leis) tenham sido produzidos em ambientes de consulta entre o Estado e a sociedade, e que organizações civis tenham se mobilizado para participar efetivamente dessas consultas, as experiências com os processos de preparação e aprovação do regulamento das associações, da Lei de Terras, da Lei do Investimento Estrangeiro e da própria Lei Constitucional, entre outros, demonstram que as instituições do Legislativo e do Executivo angolanos continuam pouco abertas ao debate de idéias e à incorporação das visões e expectativas de atores não-estatais (Abreu, 2006, p. 34).

Além disso, no bojo da sociedade civil angolana, existe a sensação de que reside na própria estrutura do Estado a dificuldade de desenvolver uma maior participação das organizações na construção de políticas. O Orçamento Geral do Estado (OGE) de Angola, por exemplo, não repassa nenhum recurso financeiro para o município, muito menos para a comuna. ${ }^{36} \mathrm{O}$ poder está centralizado no governador da província, que tem muita dificuldade em dialogar com as organizações da sociedade civil angolana, assim

\footnotetext{
35. É comum a acusação de desrespeito de ambos os lados. Segundo o diretor-geral da Unidade Técnica de Coordenação de Ajudas Humanitárias (instituição do governo que tenta controlar ações de organizações formais da sociedade civil), Pedro Ualipi Calenga, "diversas ONGs desenvolvem ações contrárias à lei, de desobediência ao governo e às instituições". O sociólogo Simão Helena, falando ao jornal estatal angolano, chega a defender a expulsão das organizações que operam no país e afirma que, "quando isso acontecer, se forem expulsas ou impedidas de exercer as suas atividades, vão se levantar vozes falando da violação dos direitos humanos e evocando outros princípios" (Jornal de Angola, 11 de julho de 2007).

36. Angola está dividida em 18 províncias, 164 municípios e 578 comunas (menor nível administrativo). O governador chefia a província, e os níveis inferiores do poder autárquico ficam a cargo de administradores. O presidente nomeia todos esses funcionários. Apenas o governador da província recebe parte do Orçamento Geral do Estado, o que demonstra grande centralização política e financeira.
} 
como essas instituições, que trabalham principalmente como organizações de base e relacionadas com o poder local, têm pouca chance de acesso ao governador da província. $\mathrm{O}$ excesso de centralização política e administrativa em Angola é mais um fator que dificulta a participação da sociedade civil e não contribui para a democratização do país.

Ainda hoje é frequiente atribuir todos os malefícios da vida política, social e econômica ao período fascista colonial português e ao leninismo, do partido único do MPLA, o que, para Fernando Pacheco, não é verdadeiro. De acordo com esse autor, tanto as práticas fascistas (como o culto ao chefe, por exemplo) como as leninistas (submissão à direção centralizadora) são também complementadas pela matriz cultural bantu, ${ }^{37}$ na qual, tradicionalmente, líderes e chefes não têm o costume de prestarem contas aos liderados ${ }^{38}$ no sentido de dar satisfação, de apresentar resultados de uma ação de que se é incumbido, o que hoje têm efeitos perniciosos na sociedade (Pacheco, 2004, p. 79).

Além de tudo isso, resta saber qual papel terá a sociedade civil ao longo do processo eleitoral. ${ }^{39}$ Essa é uma questão extremamente importante, já que as organizações que não se envolveram com a guerra ficaram ausentes dos processos de cessar-fogo de Bicesse e Lusaka. Ademais, como foi mostrado no artigo, nos últimos anos da guerra, percebeu-se claramente uma maior participação da sociedade angolana em termos de mobilização no que diz respeito ao fim do conflito.

Sobre esse aspecto são lançados desafios significativos à sociedade angolana. Em sociedades pós-conflito, existe uma idéia antecipada do cidadão e da sociedade civil que se orientam quase sempre para o comportamento dos polí-

37. Em Angola, a maioria étnica vem dos bantos. Em muitos casos, partilham hábitos e costumes comuns.

38. Isso tanto acontece em nível da família, como da comunidade e da nação.

39. Depois do fim do conflito armado, em 2002, esperavam-se eleições rapidamente. No entanto, até hoje elas não ocorreram. Está prevista uma eleição legislativa para 2008 e para o Executivo em 2009. A sociedade civil tenta pressionar o governo para antecipar os prazos, acusando o presidente de tentar perpetuar-se no cargo (vale dizer que José Eduardo dos Santos é o terceiro presidente na África há mais tempo no poder). ticos, ou seja, sobre como vão ser as ações dos candidatos em campanha eleitoral e com relação ao anúncio dos resultados finais. Essa preocupação encerra em si uma outra inquietação, a manutenção e a consolidação da paz, pois o cidadão não quer que seu voto resulte em violência política ${ }^{40}$ (Mazula e Mbilana, 2003, p. 1).

Boaventura Sousa Santos aponta quatro grandes desafios para o Estado e para a sociedade angolana nesse contexto de paz. O primeiro é o da desigualdade social. Angola é um país riquíssimo, e a esmagadora maioria do seu povo vive na miséria. A guerra serviu, até agora, para encobrir que é nas desigualdades que reside uma das mais persistentes continuidades entre a Angola colonial e a Angola pós-colonial.

O segundo desafio é o da construção de um Estado democrático, eficiente e íntegro. Nesse contexto, reconhece Santos, o peso da herança do Estado colonial é muito forte. Todavia está longe de explicar tudo. ${ }^{41}$

O terceiro desafio é o da construção de um modelo político, social e cultural genuinamente angolano, um modelo que assuma o legado cultural do país (preexistente ao colonialismo) e o faça de maneira não tradicionalista, ou seja, em nome de uma racionalidade mais ampla que a ocidental e de uma modernidade menos imperial e mais multicultural do que a imposta pelo colonialismo e pela globalização neoliberal.

Finalmente, o quarto desafio, para Santos, consiste na reconciliação nacional. As tarefas de reconciliação são particularmente fundamentais para Angola, porque não dizem respeito exclusivamente à reconciliação entre os inimigos da guerra civil, ${ }^{42}$ mas também à construção de

40. Os próprios autores, que falam da experiência eleitora em Moçambique, reconhecem que ainda são poucas as experiências práticas das organizações da sociedade civil sobre prevenção de conflitos eleitorais (2003, p. 4). Daí a importância crescente dos estudos sobre o tema.

41. Esse desafio, para o autor, confronta dois grandes obstáculos. O primeiro é o da corrupção, ou seja, a privatização do Estado por parte da elite no poder. O segundo obstáculo é o da difícil interiorização da mentalidade democrática por parte das forças políticas que conduzem a transição democrática. O Partido Único acaba não deixando de sê-lo, mesmo sendo reconhecida a existência de outros partidos e de se aceitar a disputa eleitoral.

42. Embora se perceba a dificuldade em diversas ocasiões de conciliar o MPLA e a Unita. Tensões políticas ainda ocor- 
uma sociedade democrática em Angola, o que pressupõe que, para quebrar definitivamente a fragmentação que caracterizou o governo do MPLA desde a independência, Angola deverá ter a coragem de construir concretamente uma comissão de reconciliação (Santos, 2003, p. 1-2).

\section{Considerações finais}

O setor da sociedade civil no mundo (e também em Angola) não está emergindo somente como um claro ator social, mas também como um ator diverso na sua natureza e composição. No caso angolano, a experiência colonial trouxe autoritarismo e repressão à sociedade. O ideal marxista-leninista do Partido Único, após a independência, impôs severos limites à participação de atores não-estatais e só fez aumentarem a sensação da falta de liberdade e a dificuldade da participação social da população.

Além disso, o conflito armado das décadas de 1980 e 1990 também contribuiu para uma cultura do medo, da violência e da desconfiança por parte da população de Angola.

Assim, pode-se afirmar que são grandes os desafios da sociedade civil organizada angolana nesse contexto de paz. A busca pela participação social e o fortalecimento das frágeis instituições democráticas parecem-me os elementos mais importantes para a manutenção da paz.

Para isso, torna-se fundamental a valorização das diversas culturas angolanas. A sociedade civil deve pautar-se em buscar políticas que respeitem os variados aspectos de sua cultura para que não seja forjada uma organização civil artificial, à medida que se distancia das diversas realidades daquele país.

Por sua vez, o governo deve buscar maior apoio da sociedade angolana para desenvolver melhor as suas políticas. Num país com baixíssimo índice de desenvolvimento humano, o governo não tem conseguido dar assistência mínima para a população. Por isso é fundamental

rem no país; um exemplo é fornecido pelo jornal Ondaka, da ONG canadense Development Workshop, em Huambo, em texto no qual afirma que deputados da Unita foram apedrejados por populares numa tentativa de encontro com a administração local, entidade religiosas e tradicionais. Inúmeros foram os feridos. Ao explicar os motivos da agressão, os populares disseram querer vingança e fazer justiça. In: Jornal Ondaka, no 38, Huambo, 2004. a parceria com a sociedade civil que, muitas vezes, tem um maior conhecimento da região ou do contexto local. Isso pode valorizar ações mais prioritárias, principalmente se lembrarmos que boa parte do território angolano ainda não é totalmente conhecida pelos governantes por ter sido área de influência de outro movimento armado em conjuntura recente de guerra.

É extremamente importante a descentralização política e também administrativa em Angola para o aumento da participação da sociedade civil na elaboração de políticas públicas. Além disso, um pressuposto essencial a considerar no processo de desenvolvimento local é justamente a adoção do princípio da descentralização (é claro que pressupõe também um monitoramento das ações).

Esse movimento de descentralização deve ser acompanhado por movimentos de democratização, na relação entre a administração pública local e setores da comunidade. Os órgãos públicos que atuam como setores técnicos-administrativos, nos procedimentos de prestação de serviços, necessitam negociar e receber a influência de outros atores interessados nos resultados da sua ação.

Por meio desta, a autoridade e o comando para as realizações podem ser transferidos para os níveis de execução que estão mais próximos de onde os resultados finais são obtidos. Para que a descentralização e a participação sejam instrumentos efetivos no processo de desenvolvimento local, é preciso que se cultive um clima social cooperativo. ${ }^{42}$

Dessa forma, afirmo também que a falta de recursos financeiros está na base da debilidade das organizações da sociedade civil, que ficam dependentes dos doadores internacionais. ${ }^{43}$ Exceto, claro, a Fundação Eduardo dos Santos e as demais que foram criadas e giram em torno da esfera do poder, como a Organização das Mulheres Angolanas do MPLA, o Fundo Lwini (ambas da primeira-dama Ana Paula dos Santos), entre outras.

\footnotetext{
42. A formação de redes fortalece a comunidade em torno de um objetivo comum de desenvolvimento.

43. Em muitos casos, essa dependência financeira é também uma dependência de agendas, com as organizações abandonando seus objetivos sociais aos quais estavam ligadas inicialmente.
} 
Acredito que a melhoria das condições de sobrevivência da população e o combate à pobreza no país só acontecerão como resultado do trabalho conjunto entre o governo e a sociedade civil, sendo fundamental superar todos os constrangimentos que ainda persistem.

Angola não pode cometer os equívocos do passado recente. A prevenção do conflito também é função da sociedade civil. Diversas tensões políticas ocorrem ainda no país. Isso mostra a enorme tarefa que tem a sociedade angolana em termos de "pacificar os espíritos".

Diante disso, o verdadeiro despertar dessa sociedade civil organizada que busca ser reconhecida de forma democrática, participativa e respeitadora da diversidade presente no país é fundamental, pois dessa maneira os grandes desafios sociais que ainda persistem em Angola poderão ser enfrentados de forma mais eficaz.

\footnotetext{
Abstract: The article intends to after point the new ways developed for the Angolan civil society the ticket of the First Republic, characterized for a State of Party Only and inhaled in the marxist and leninist ideals, for the Second Republic, that is, for a market economy, demonstrating the happened adversities of the diverse social, politics and cultures realities of the Angolan territorial space resultant of the settling process, for the formation and consolidation of the democracy and of the civil society in Angola. To do that, I used an updated and revised bibliography about the theme and some interviews in Luanda. The conclusion was that the political and administrative power in Angola is very centralized and inhibits the participation of the civil society in public policies.
}

Key-words: Angolan civil society; democracy; market economy.

\section{Referências}

ABREU, Cesaltina Cadete Basto de. Sociedade civil em Angola: da realidade à utopia. Rio de Janeiro, 2006. Tese (Doutorado) - Ucam/Iuperj.

ANDERSON, Perry. Portugal e o fim do ultracolonialismo. Rio de Janeiro: Ed. Civilização Brasileira, 1966.

COHEN J. e ARATO A. Civil society and political theory. Cambridge: MIT Press, 1992.

COMERFORD, Michael G. The peaceful face of Angola: biography of a peace process (1991 to 2002). Windhoek: John Meinert Printing, 2005.
DAVIDSON, Basil. Angola no centro do furacão. Lisboa: Edições Delfos, 1974.

O fardo do homem negro: os efeitos do Estado-nação em África. Luanda: Edições Chá de Caxinde, 2000

FREUDENTHAL, Aida. Um partido colonial Partido Reformista de Angola - 1910-1912. Revista Internacional de Estudos Africanos, Lisboa, Instituto de Investigação Científica Tropical. Centro de Estudos Africanos e Asiáticos, nº 8-9, 1988.

GONÇALVES, José. O descontínuo processo de desenvolvimento democrático em Angola. Lisboa, ISCTE, Centro de Estudos Africanos, 2004.

HUMAN RIGHTS WATCH. Briefing sobre Angola apresentado ao Conselho de Segurança da Organização das Nações Unidas ao Abrigo da Fórmula Arria. Nova York, março, 2002.

LOPES, Carlos. A pirâmide invertida-Historiografia africana feita por africanos. Colóquio: construção e ensino da história da África. Lisboa: GTCDP, 1995.

LOPES, Filomeno Vieira. The challenges of democratization. From military peace to social justice? The Angolan peace process. Londres: Accord, 2004.

MAXWELL, Kenneth. O império derrotado. Revolução e democracia em Portugal. São Paulo: Cia. das Letras, 2006.

MAZULA, Brazão e MBILANA, Guilherme. O papel das organizações da sociedade civil na prevenção, gestão e transformação de conflitos: a experiência de Moçambique. Luanda, 2003.

MATIAS, Nicásia Casimiro. Os boers portugueses da Humpata: um fracasso na política de assimilação portuguesa?. In: SEMINÁRIO: ENCONTROS DE POVOS E CULTURAS EM ANGOLA. Anais... Luanda: Ministério da Cultura de Angola, 2007.

MEIJER, Guus. Lessons from the angolan peace process. From military peace to social justice? The angolan peace process. Londres: Accord, 2006.

MESSIANT, Christine. A Fundação Eduardo dos Santos (Fesa). A propósito da investida do poder angolano sobre a sociedade civil. Politique Africaine, $\mathrm{n}^{\circ} 70,1999$.

MIGUEL, Adão Avelino. Cidadania e civismo: entre a interpretação e a reinterpretação da sociedade civil angolana. Lucere. Revista Acadêmica da Universidade Católica de Angola, Luanda, Centro de Estudos e Investigação Científica, nº 3, 2006.

PACHECO, Fernando. Democracia e sociedade civil em Angola. Lisboa: Instituto de Estudos Estratégicos, 1994.

Uma proposta de valorização da tradição e da cultura em favor do desenvolvimento e moder- 
nidade. Lucere. Revista Acadêmica da Universidade Católica de Angola. Luanda, Centro de Estudos de Investigação Científica, $\mathrm{n}^{\circ}$ 1, 2004.

PAIN, Rodrigo de Souza. ONGs e segurança alimentar na África: cooperação, interesses e conflitos. Revista Transdições, Rio de Janeiro, Pontifícia Universidade Católica, 2006.

PESTANA, Nelson. As dinâmicas da sociedade civil em Angola. ISCTE. Lisboa: Centro de Estudos Africanos, 2004.
SANTOS, Boaventura Sousa. Angola na viragem. Revista Visão, Lisboa, agosto, 2003.

VINES, A. Peace postponed, Angola since the Lusaka Protocol. Londres: CIIR,1998.

La troisième guerre angolaine. Politique Africaine, $\mathrm{n}^{\circ}$ 57, Paris, 1995. 
